\title{
Comparison of Oestrous Synchronization Response and Pregnancy Rate of Village Cows Following Timed Artificial Insemination in KwaZulu-Natal and Limpopo Provinces
}

\author{
Ayanda Maqhashu',2, Masindi L. Mphaphathi', Mokgadi M. Seshoka1, \\ Fhulufhelo V. Ramukhithi', Frans L. Seolwana1, Matshidiso B. Masenya1, \\ Thivhilaheli R. Netshirovha ${ }^{1}$, Mohleko H. Mapeka ${ }^{1}$, Nkhanedzeni B. Nengovhela ${ }^{1}$, \\ Noel L. Kanuya3 ${ }^{3}$, Voster Muchenje ${ }^{2}$, Tshimangadzo L. Nedambale 1,4,5*

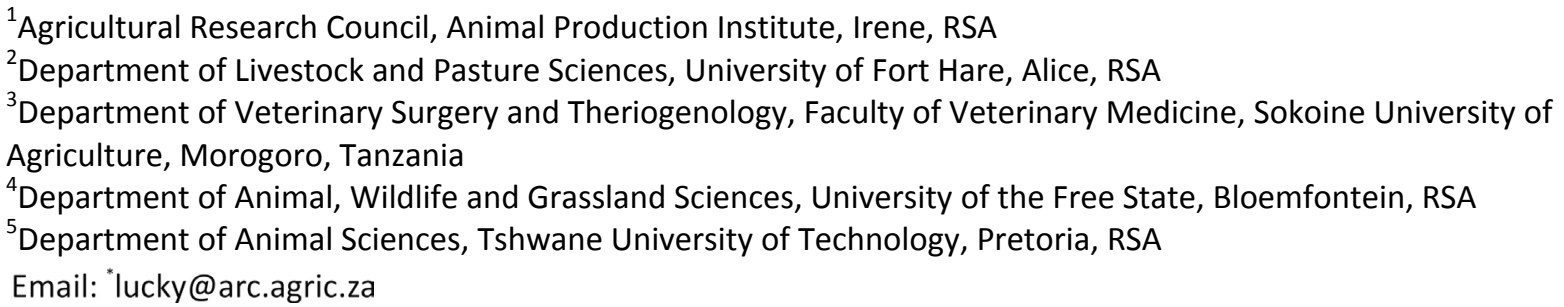

Received 2 October 2015; accepted 9 January 2016; published 12 January 2016

Copyright (C) 2016 by authors and Scientific Research Publishing Inc.

This work is licensed under the Creative Commons Attribution International License (CC BY). http://creativecommons.org/licenses/by/4.0/

\section{Open Access}

\section{Abstract}

The objectives of the current study were to evaluate the estrous response and pregnancy rate following timed artificial insemination (TAI) with frozen-thawed semen in cows. The study was carried out in cows at different villages of KwaZulu-Natal $(K Z N ; n=160)$ and Limpopo provinces $(L ; n$ = 171). Cows were selected randomly as presented by the farmers, regardless of parity, age, breed and body weight following pregnancy diagnosis. The cows were grouped according to breed type and body condition score (BCS) on a scale of 1 - 5. Selected cows were inserted a controlled intravaginal drug release (CIDR ${ }^{\circledR}$ ) and removed on day 8 , followed by administration of prostaglandin. Heat was observed on day 9 with the aid of heat mount detectors (HMD) that were placed on the individual cow's tail head. Cows on heat were then inseminated twice at 12 hours interval. Pregnancy diagnosis was performed by an ultra-sound scanner and rectal palpation 90 days after TAI. Data were analyzed using SAS 2006. Estrous responses were $100 \%$ in KZN and 99\% in Limpopo.

\footnotetext{
"Corresponding author.
}

How to cite this paper: Maqhashu, A., et al. (2016) Comparison of Oestrous Synchronization Response and Pregnancy Rate of Village Cows Following Timed Artificial Insemination in KwaZulu-Natal and Limpopo Provinces. Open Journal of Animal Sciences, 5, 9-15. http://dx.doi.org/10.4236/ojas.2016.61002 
The lowest pregnancy rate was recorded in Brahman and Bonsmara type cows with BCS $\leq 2.5$ regardless of province. Interestingly, Nguni type cows with $\mathrm{BCS} \leq \mathbf{2 . 5}$ had higher average pregnancy rate of $59.5 \%$ in Limpopo and $53.5 \%$ in KZN. However, cows with BCS $\geq 3$ had better pregnancy rate regardless of breed type and province. In conclusion, village cows can be synchronized successfully and inseminated with frozen-thawed semen. However, pregnancy rates are low in cows with lower body condition. Village Nguni type cows were not affected by body condition scoring as they had higher and similar pregnancy rate as those that had body condition of $\geq 3$.

\section{Keywords}

Synchronization, Village Cows, Body Condition Score, Pregnancy Diagnosis

\section{Introduction}

Cattle from villages are an important but an unproductive asset for South Africa as they comprise $42 \%$ of the national herd and contribute only 5\% to South Africa's gross domestic product from beef industry [1]. There are about 14.1 million cattle in South Africa with over 5.5 million located in the villages and are comprised of different breed types [1]. Furthermore the village cattle genetic information is unknown. Therefore, the need for livestock improvement has become more urgent in recent years with the increasing focus of the government and industries on food security [2] [3]. Village farmers rear cattle that are crosses between Bos indicus and Bos taurus that display a difference behaviorally and likely to lose the body condition unpleasantly in dry season [4]. Improvement of reproductive performance of cows in the emerging sector has the potential to improve herd quality, replacement and off take rates from smallholder farms. The indigenous knowledge and socio-economic situations alone might lead to inbreeding and unplanned genotypes, that the farmer had neither experience nor resources to manage [5].

Indigenous cattle breeds are currently subjected to fast degradation and dilution because of unplanned breeding, crossbreeding and introduction of exotic germplasm [6]. Long postpartum oestrous period, low fertility, high number of services per conception, low birth weight and low average daily gain and lower weaning weight are very common problems with small holder reared cows. Increase in the beef industry and the rest of its value chain relies on the interventions that target this unproductive herd (village cattle). So achieving improvement, profitability and long-term viability of the emerging beef sector requires accessibility of the sector to all existing knowledge and technologies for better reproductive performance.

Good management practices and assisted reproductive technologies (ART) such as estrous synchronization, artificial insemination (AI) and superovulation are the rarely used but vital practices for productive and profitable cattle farming [7]. Oestrous synchronization assists in the accomplishment of faster livestock improvement programmes such as fixed time artificial insemination (FTAI) and superovulation of cows, thus minimizes costs, time and labor required for oestrous detection in cows and buying superior dams and sires [8]. In this way, the transfer of genes by AI into populations of decreased biodiversity is made possible, uniform and less costly [9] [10]. However, these ARTs are limited by a lot of intrinsic (individual animal variation, lactation status and health status) and extrinsic (nutrition and weather condition and management practices) factors.

Body condition score (BCS) of an animal may be used as a management tool for assessing the physiological states and is the most practical method of evaluating the energy reserves by the proportion of body fat all over the body [4]. It can be used in estimating returns from livestock farming and is reported to have a strong relationship with a cow's calving interval and the number of days open [4] [11] [12]. Therefore, the objectives of the present study were to evaluate the estrous response and pregnancy rate following FTAI with frozen-thawed semen on different breeds of cattle found in emerging farmers of KwaZulu Natal and Limpopo province.

\section{Materials and Methods}

\subsection{Location and Experimental Cows}

The study was carried out on small holder village cattle of KZN (Nogejane, Besters, Mphuzanyoni, Manzabilayo, Driefontein, Fitty Park, Machibini and Mthandi) $(n=160)$ and Limpopo (Vhalinavho, Vuvha, Muyexe, 
Ga-Nkidikitlana, Dikgokgopeng, Taulomme, Bilangfontein, Ha-Masekona, Legrwareng and Prospect) $(\mathrm{n}=171)$ following training intervention. Cows were selected randomly, with the criteria of being non-pregnant and have a normal reproduction cycle, given birth before, regardless of parity, milk yield, age, breed and body weight. Selected cows were synchronized and FTAI during the December-March (2013/2014) breeding season. The cows were grouped according to breed type and BCS into two groups on a scale of (1-5) where 1 is severely emaciated, 2 partially emaciated, 3 moderate, 4 partially fat and 5 too fat. The types of breeds were identified at the time of oestrous synchronization and BCS were recorded before and after synchronization. The breeds were identified by their phenotypic traits of resemblance of Nguni type (phenotypically resembled Nguni cattle breed), Brahman type (phenotypically resembled Brahman cattle breed) and Bonsmara (phenotypically resembled Bonsmara cattle breed).

\subsection{Oestrous Synchronization}

Experimental cows in all the groups were synchronized using an Ovsynch protocol that utilizes a Gonadotropin releasing hormone (GnRH) and prostaglandin (PGF2 $\alpha$ ). A controlled intravaginal drug release (CIDR ${ }^{\circledR}$ ) device containing $1.9 \mathrm{~g}$ progesterone was inserted in the vagina of each cow on Day0 with an intramuscular injection (i.m) of estradiol benzoate (EB). On Day5, cows were injected with a GnRH i.m to assist in the follicular growth. The CIDR $^{\circledR}$ was removed on the $8^{\text {th }}$ day as per protocol and a PGF2 $\alpha$ (Estrumate ${ }^{\circledR}$, Schering-Plough Animal Health, USA) injection was administered i.m. Another i.m injection of EB that is half of the one administered at Day 0 was given to the cows on Day 9. Heat mount detector (HMD) device that is white in colour was mounted with glue on the tail head of each cow. The heat detector device changes colour to red when the cow was mounted (indicating that the cows responded to the synchronization protocol).

\subsection{Artificial Insemination}

The FTAI of the cows was performed 12 hours after the EB injection at the time of standing heat. Frozenthawed semen of registered Nguni bulls of superior fertility was used. Cows were inseminated twice at 12 hours interval. The sperm motility rate (non-progressive, progressive, slow, medium and rapid) and the velocity on the curve line were evaluated and recorded using a Sperm Class Analyzer ${ }^{\circledR}\left(\mathrm{SCA}^{\circledR}\right.$-Microptic, Spain) system before freezing and FTAI. Bulls with sperm motility results of $\geq 75 \%$ were used for AI.

\subsection{Pregnancy Diagnosis (Figure 1)}

Pregnancy status was diagnosed after 90 days following FTAI by transrectal ultrasonography of the reproductive

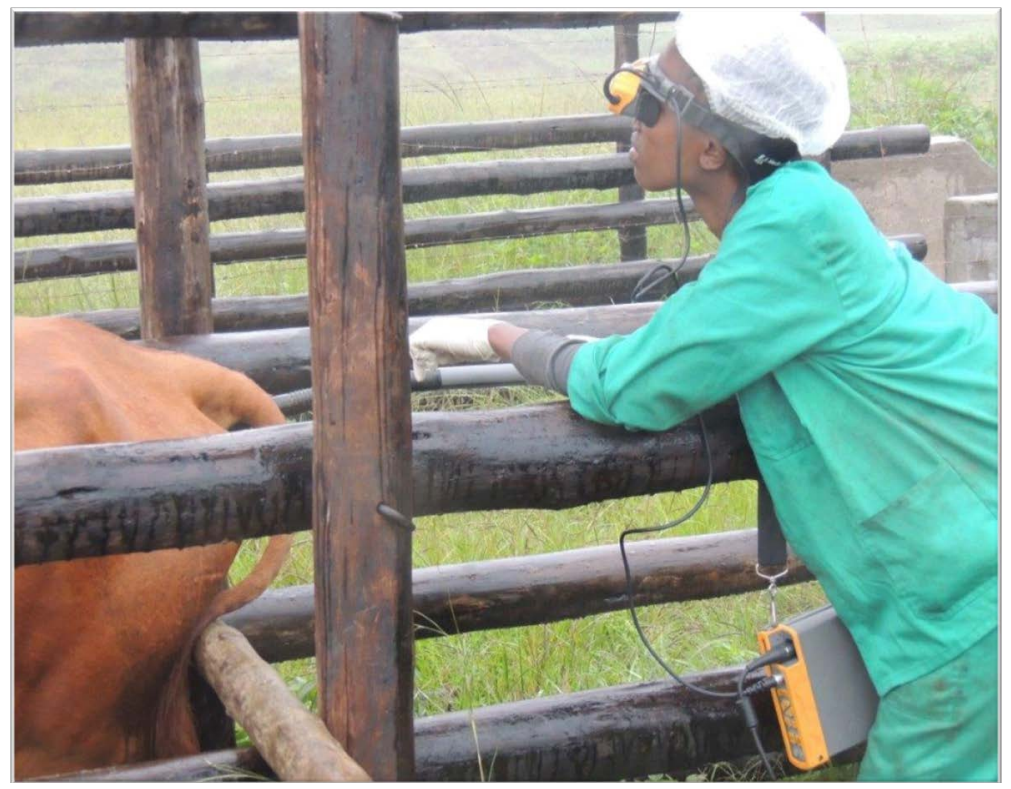

Figure 1. Pregnancy diagnoses with an ultrasound scanner. 
tract and rectal palpation. Observations of embryonic fluid, appearance of the embryo or embryonic heartbeat were used as determinants of pregnancy. Pregnancy per AI was calculated per province after FTAI. The side of corpus luteum (CL) formation was palpated in all pregnant cows.

\subsection{Data Analysis}

The proportions of cows that had HMDs that changed colour or showed estrous after removal of the CIDR ${ }^{\circledR}$ and PGF2 $\alpha$ injection as well as pregnancy rate was analyzed by separate Chi-square analyses using the Frequency Procedure of SAS Ver. 9.1.3 (SAS, 2006).

\section{Results (Figure 2)}

Table 1 indicated that in KZN province, there was a 100\% response of estrous synchronization in all the breed types (Nguni, Brahman and Bonsmara type cows) while Limpopo province there was $99 \%$ response. The pregnancy rate was lowest on the cows with BCS $\leq 2.5$ among the breed types; Brahman (25\%), Bonsmara (29\%)

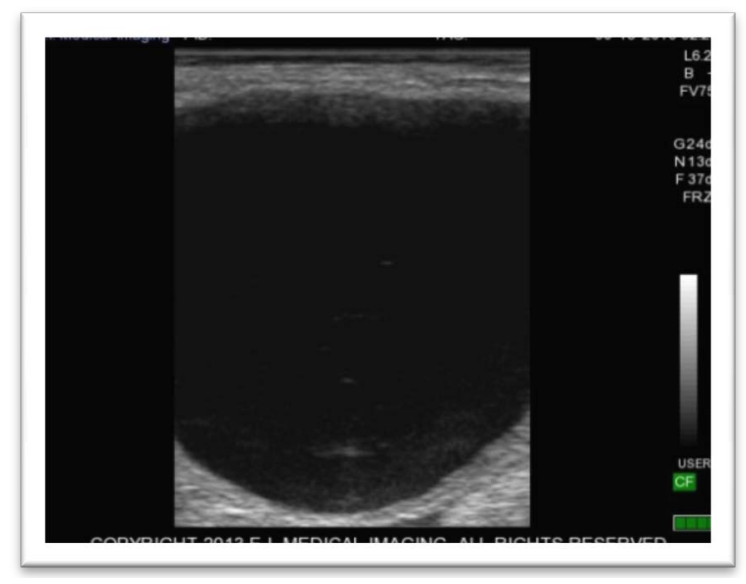

(a)

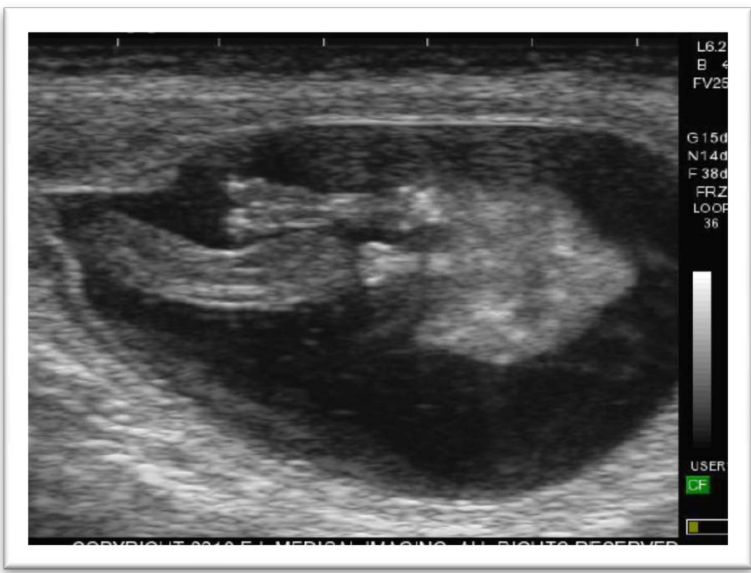

(b)

Figure 2. (a) Non pregnant cow (b) Pregnant cow as observed on the scanner.

Table 1. The pregnancy percentage amongst different breeds type after oestrous synchronization and artificial insemination by frozen-thawed semen in Limpopo and KwaZulu-Natal provinces.

\begin{tabular}{|c|c|c|c|c|c|}
\hline Provinces & Breed types & Body conditions score & $\begin{array}{l}\text { Cows } \\
\text { (n) }\end{array}$ & $\begin{array}{l}\text { Synchronization } \\
\text { response (\%) }\end{array}$ & Pregnancy rate (\%) \\
\hline \multirow{6}{*}{ Limpopo } & Brahman & $\leq 2.5$ & 24 & 96 & $25^{\mathrm{a}}$ \\
\hline & Brahman & $\geq 3$ & 15 & 100 & $60^{\mathrm{b}}$ \\
\hline & Bonsmara & $\leq 2.5$ & 28 & 100 & $29^{\mathrm{a}}$ \\
\hline & Bonsmara & $\geq 3$ & 21 & 100 & $61^{\mathrm{b}}$ \\
\hline & Nguni & $\leq 2.5$ & 19 & 100 & $57^{\mathrm{b}}$ \\
\hline & Nguni & $\geq 3$ & 65 & 100 & $62^{\mathrm{b}}$ \\
\hline \multirow{6}{*}{ KwaZulu Natal } & Brahman & $\leq 2.5$ & 30 & 100 & $36^{\mathrm{a}}$ \\
\hline & Brahman & $\geq 3$ & 20 & 100 & $45^{\mathrm{a}}$ \\
\hline & Bonsmara & $\leq 2.5$ & 31 & 100 & $35^{\mathrm{a}}$ \\
\hline & Bonsmara & $\geq 3$ & 19 & 100 & $52^{\mathrm{b}}$ \\
\hline & Nguni & $\leq 2.5$ & 20 & 100 & $45^{\mathrm{a}}$ \\
\hline & Nguni & $\geq 3$ & 50 & 100 & $60^{\mathrm{b}}$ \\
\hline
\end{tabular}


and an exception was observed with the Nguni type cows as (57\%) pregnancy was observed in Limpopo province. Cows with BCS of $\geq 3$ had better pregnancy rate of 60, 61and 62\% in Limpopo province. Similar results were observed in KZN, lower pregnancy rate was recorded on the cows with BCS $\leq 2.5$ (36, 35 and 45 in Brahman, Bonsmara and Nguni breed types), but better in cows with BCS $\geq 3$ in 45, 52 and $60 \%$ in Brahman, Bonsmara and Nguni breed types.

\section{Discussion}

It was demonstrated that village cows regardless of breed type, body condition and province were successfully synchronized and artificially inseminated with frozen-thawed sperm and carry pregnancy to calving. Heat mount detectors were helpful to obverse which cows came to heat. However, pregnancy and calving rate was low in cows with BCS of $\leq 2.5$. Heat detection is reported to be a tough and a labor intensive task that most breeders miss and end up not inseminating cows in time [13]. For an economic beef production high pregnancy rates are vital. Infertility in cattle is mostly associated with female failing to show signs of heat and releasing an egg after every 21 days (estrous cycle). Bruno et al., [13] reported that with good oestrous detection method it is almost impossible to miss cows that responded to the synchronization protocols. Results from a similar study where two oestrous synchronization treatments were used oestrous was detected in $88 \%$ of cows from group 1 (G1) where progesterone was not supplemented and 95\% from group 2 (G2) progesterone supplemented. Pregnancy rate results showed $75 \%$ of cows from G1 and $85 \%$ from G2, this indicates that a good oestrous synchronization program can result to higher response and resulting pregnancy rates in well managed cows [14].

The results on the current study are similar to the observations found in the Madura beef cows where the response was high (75\%) for oestrous synchronization but overall conception was lower (66.6\%) due to most cows that had low BCS [4]. Wildeus, [15], reported that nutritional status of cow peripartum after oestrous synchronization influenced conception rate and postpartum ovarian cycles. Cows with BCS $\geq 4$ and $\leq 2.5$ are reported to have a delayed onset of estrous [4]. Cows with BCS of 2.5 or less have displayed conception rates vividly lower with the exception of Nguni type in both provinces and in all the three breeds. The Nguni cows had higher pregnancy rates than Bonsmara and Brahman, the majority of the Bonsmara and Brahman cattle had very low BCS in these villages and also their conception rate were reduced [16] [17]. The Nguni cattle are adapted to harsh conditions and do not require supplementation and veterinary interventions, their reproduction performance is not compromised [18] [19]. Reproduction characteristics are affected by loss of condition in cows before calving the best performances were recorded in females with medium BCS 2.75 to 3.50 [14].

Similar results were reported by [4] where BCS was highly related to reproductive performance: thinner cows showed lower reproductive performance, whereas higher BCS had positive associations with days to first oestrous, interval to first service and conception rate at first service. The results of the current study for lower pregnancy rates might be due to diseases and nutrition but the communal pasture setting provides a unique environment for the study of disease and herd problems [20]. It represents a combination of cows from a variety of management systems (vaccinated and non-vaccinated), brought together as a group for the breeding and grazing season. It also poses a challenge when it comes to controlling infectious disease, because of the intermingling of animals from different herds [2] [20]. Hence it makes it difficult to identify whether cows get adequate feed or not. In addition to low nutritional status and BCS, there was no strict separation of calves from their mothers due to lack of camps and limited grazing lands. The farmers allowed the calf to suckle the mother until it was naturally weaned. In dry season, this practice is harder for the cows as they do not get enough nutrient supply for milk synthesis. As a consequence, nutrients reserve in the body is mobilized to compensate nutrient required for milk production, this results in cows losing their body condition during lactation. The higher pregnancy rate was observed in Nguni type cows in the villages of both provinces. Nguni cattle breed has been reported to be resistant to infection such as trypanosomiasis, opthalmia, heart water and other tick-borne diseases and tick infestations [21]. The breed show exceptionally good fertility under harsh conditions, with excellent reproductive performance [22]. Nguni cattle are less susceptible to dystocia, this being ascribed to their small uterus and low birth weight [19]. Ngunis are excellent foragers and will graze and browse on steep slopes and in thick bush. They fatten well on natural grazing [23]. They have long productive lives; cows calve regularly and produce 10 or more calves. The experiment was only limited to cows from parity $1-6$. Similar results were observed on Madura cows where the highest AI success was achieved in cows with BCS 3.5 (75.0\%). Cows on acceptable BCS 3 - 4 that do not conceive after oestrous synchronization and AI are problematic its either they are sick, late 
calvers and infertile. Cows that calve early will have more days postpartum before the beginning of the next breeding season. Thus, as compared to late calving cows, early calving cows will have resumed normal oestrous cycles and fertility by the beginning of the next breeding season [24].

Increased fertility for cows artificially inseminated upon oestrous detection has been reported [2] [25] [26] and is most likely due to the cows completing the FTAI protocol. Most of the cows that did not conceive are cows that were not identified in oestrous because they experienced some issue such as false oestrous, negative energy balance, uterine or metabolic diseases, asynchrony to the reproductive program [15]. However, even though cows were detected on estrous, pregnancy rate were highly affected by the body condition of cows. As reported by [15] cows that do not maintain adequate body condition going into the calving and breeding seasons, will usually have reduced conception rates and consequently, higher culling rates. However, lower BCS is generally related to the lower progesterone levels in the blood and over conditioned cows have been reported to have a higher risk of dystocia and metabolic disorder [20].

\section{Conclusion}

The village cows were synchronized successfully for oestrous regardless of the breed, BCS and the geographical area. Pregnancy rate was lower in breed types that had BCS less than 2.5 on a scale of $1-5$. Frozen-thawed semen can be used for FTAI to improve pregnancy rates of village cows with BCS of 3 - 4.5. The results that were obtained in the study showed that FTAI had a potential of increasing use of superior bulls to improve the genetic material if only the BCS could be improved by reducing the number of older animals, vaccinating the whole herd, culling infertile animals and reducing the stocking rate in accordance to the carrying capacity of the veld.

\section{Acknowledgements}

The authors gratefully acknowledge the financial support from the Technology Innovation Agency (TIA), Agricultural Research Council (ARC) and Govern Mbeki Research Development Centre (GMRDC).

\section{References}

[1] Musemwa, L., Mushunje, A., Chimonyo, M., Fraser, G., Mapiye, C. and Muchenje, V. (2008) Nguni Cattle Marketing Constraints and Opportunities in the Communal Areas of South Africa: Review. African Journal of Agricultural Research, 3, 239-245.

[2] Hanotte, O., Bradley, D.G., Ochieng, J.W., Verjee, Y., Hill, E.W. and Rege, J.E. (2002) African Pastoralism: Genetic Imprints of Origins and Migrations. Science, 296, 336-339. http://dx.doi.org/10.1126/science.1069878

[3] Suzuki, K.M., Kanameda, S., Tachibana, T., Ogawa, T., Tisdang, D. and Pffiffer, U. (2006) A Monitoring Study on Cattle Growth and Body Condition in Smallholder Dairy Farming System in Northern Vietnam. Journal of Veterinary Epidemiology, 10, 15-20. http://dx.doi.org/10.2743/jve.10.15

[4] Ciptadi, G., Nasich, M., Budiarto Nuryadi, A. and Nurgiartiningsih, V.M.A. (2012) The Oestrous Synchronization Response Following PGF2 $\alpha$ Treatment in Indonesian Madura Cattle with Different Body Condition Scores. Journal of Animal and Veterinary Advance, 11, 676-680.

[5] Food and Agriculture Organization (2013) Communal Area Livestock Management Systems in Zimbabwe. http://www.fao.org

[6] Santos, I.W., Weiss, R.R. and Kozicki, L.E. (2000) Oestrous Synchronization in Beef Cows. Archives of Veterinary Science, 5, 1-4.

[7] Webb, R., Garnsworthy, J., Gong, G. and Armstrong, D.G. (2004) Control of Follicular Growth: Local Interactions and Nutritional Influences. Journal of Animal Science, 82, 63-74.

[8] Larson, R.L. and Randlea, R.F. (2013) The Bovine Oestrous Cycle and Synchronization of Oestrous. http://www.extension.iastate.edu

[9] Lopes da Costa, L., Chagas e Silva, J. and Silva, J.R. (2001) Superovulatory Response, Embryo Quality and Fertility after Treatment with Different Gonadotrophins in Native Cattle. Theriogenology, 56, 66-77. http://dx.doi.org/10.1016/S0093-691X(01)00543-X

[10] Wardynski, F. (2013) Check Beef Cow Body Condition to Improve Reproductive Performance. http://www.msue.msu.edu

[11] Berry, K.L., Buelow, H.E., Hall, D.H. and Hobert, O. (2003) A C. elegans CLIC-Like Protein Required for Intracellular Tube Formation and Maintenance. Science, 302, 2134-2137. 
[12] Schroeder, U.J. and Staufenbiel, R. (2006) Methods to Determine Body Fat Reserves in the Dairy Cow with Special Regard to Ultrasonographic Measurement of Backfat Thickness. Journal of Dairy Science, 89, 1-14. http://dx.doi.org/10.3168/jds.S0022-0302(06)72064-1

[13] Bruno, R.G.S., Farias, A.M., Hernández-Rivera, J.A., Navarrette, A.E., Hawkins, D.E. and Bilby, T.R. (2013) Effect of Gonadotropin-Releasing Hormone or Prostaglandin F2 $\alpha$-Based Oestrous Synchronization Programs for First or Subsequent Artificial Insemination in Lactating Dairy Cows. Journal of Dairy Science, 96, 1556-1567. http://dx.doi.org/10.3168/jds.2012-5885

[14] Rani, Z.T., Chimonyo, M., Hugo, G., Marume, U. and Muchenje, V. (2011) Effect of Parity on the Proximate Composition and Fatty Acid Profile of Milk from Nguni Cattle Grazing on Natural Pastures. African Journal of Biotechnology, 10, 8647-8653.

[15] Wildeus, S. (2000) Current Concepts in Synchronization of Oestrous: Sheep and Goats. Journal of Animal Science, 77, $1-14$.

[16] Nedambale, T.L. (2012) Business Newspaper. http://www.fin24.com

[17] Bruno, R.G.S., Moraes, J.G.N., Hernandez-Rivera, J.A., Lager, K.J., Silva, P.R.B., Scanavez, A.L.A., Mendonca, L.G.D., Chebel, R.C. and Bilby, T.R. (2011) Comparison of Two Resynchronization Protocols Initiated at Different Intervals after Insemination on Fertility in Lactating Dairy Cows. Journal of Dairy Science, 94, 60-69.

[18] Lucy, M.C., Savio, J.D., Badinga, L., De La Sota, R.L. and Thatcher, W.W. (1992) Factors that Affect Ovarian Follicular Dynamics in Cattle. Journal of Animal Science, 70, 3615-3626.

[19] Nqeno, N., Chimonyo, M., Mapiye, C. and Marufu, M.C. (2009) Ovarian Activity, Conception and Pregnancy Patterns of Cows in the Semiarid Communal Rangelands in the Eastern Cape Province of South Africa. Animal Reproduction Science, 118, 140-147. http://dx.doi.org/10.1016/j.anireprosci.2009.07.006

[20] Scholtz, M.M. (2005) The Role of Research and a Seed Stock Industry in the in Situ Consercation of Licestock Genetic Resources. Proceedings of the 4th AACAA and TSAP Annual Meeting, Arusha, Tanzania, 20-24 September 2005, 313-316.

[21] Muchenje, V., Dzama, K., Chimonyo, M., Raats, J.G. and Strydom, P.E. (2008) Meat Quality of Nguni, Bonsmara and Angus Steers Raised on Natural Pasture in the Eastern Cape, South Africa. Meat Science, 79, 20-28. http://dx.doi.org/10.1016/j.meatsci.2007.07.026

[22] Muchenje, V., Dzama, K., Chimonyo, M., Raats, J.G. and Strydom, P.E. (2008) Tick Susceptibility and Its Effects on Growth Performance and Carcass Characteristics of Nguni, Bonsmara and Angus Steers Raised on Natural Pasture. Animal, 2, 298-304. http://dx.doi.org/10.1016/j.meatsci.2007.07.026

[23] Yamada, K., Nakao, T. and Isob, N. (2003) Effect of Body Condition Score in Cow Peripartum on the Onset of Postpartum Ovarian Cyclicity and Conception Rate after Ovulation Synchronization Fixed Time Artificial Insemination. Journal of Reproduction and Development, 49, 381-388. http://dx.doi.org/10.1262/jrd.49.381

[24] DeJarnette, M. (2004) Oestrous Synchronization: A Reproductive Management Tool. http://www.selectsires.com

[25] Jordan, E.R., Schouten, M.J., Quast, J.W., Belschner, A.P. and Tomaszewski, M.A. (2002) Comparison of Two Timed Artificial Insemination (TAI) Protocols for Management of First Insemination Postpartum. Journal of Dairy Science, 85, 1002-1008. http://dx.doi.org/10.3168/jds.S0022-0302(02)74160-X

[26] Kasimanickam, R., Cornwell, J.M. and Nebel, R.L. (2005) Fertility Following Fixed-Time AI or Insemination at Observed Oestrous in Ovsynch and Heatsynch Programs in Lactating Dairy Cows. Theriogenology, 63, 2550-2559. http://dx.doi.org/10.1016/j.theriogenology.2004.11.003 